\title{
砂推の波形勾配及び掃流砂量について \\ ON THE STEEPNESS OF DUNES AND THE SEDIMENT TRANSPORT
}

\author{
中央大学理工学部 正会員林 泰造 \\ 中央大学大学院学生員 $\bigcirc$ 矢内栄二
}

1. はじめに

掃流砂量の計算にはまず有効掃流力を求めるととが必要である。従来の有効掃流力 $\tau^{\prime} の$ 算定の方法はんず れも全掃流力 $\tau$, 平坦河床面としての砂粒粗度を与えて求めるすのであり, このよらにして定められた有 効掃流力を全掃流力から差し引いたものが河床抵抗 “剪断力” でであるとされてをた。しかし明らかに，で

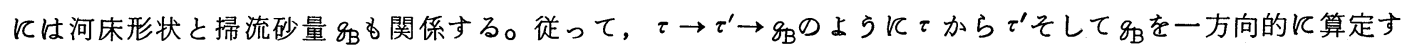

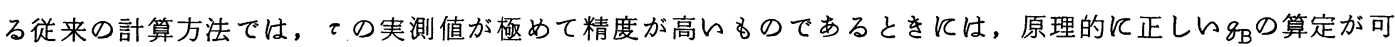

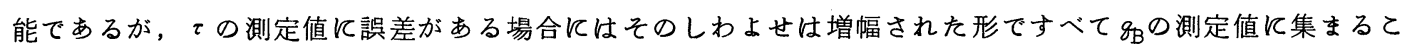
とになる。従って, 従来のでの分離方法は原理的に正しいるのであっても, 実際上の目的のためには精度の 上で不十分なるのであったといえる。てのような誤差の影響の一方向的な集中を避けるためにはての内訳で あるでどを用い，乙れに后および河床形状（すなわち河休波の卓越波長・波高）の影響を加えててに

f e ed b a ckする式をたて系を閉じて問題を”全体的に"解くことが必要である。

本研究は，てのような考え方に基づいて理論的研究を行なった。研究はまだ完成したものとなっていない が, 本論文においてはてれまでに得られた結果と問題点について報告する。

\section{2. 記号}

本論文に使用する記号はつぎのようである。（Fig.1参照）。

$\mathrm{D}:$ 水梁

凡 : 河床波の波高

L : 河床波の波長

$\mathrm{u}_{1}$ ：河床波頂断面での断面平均流速

$\mathrm{u}_{2}$ : 河床波底断面での断面平均流速

$g$ ：単位幅当り流量

Um: 断面平均流速

$\mathrm{s}$ : 砂の比重

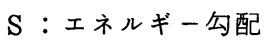

$\mathrm{d}$ ：河床砂の粒径

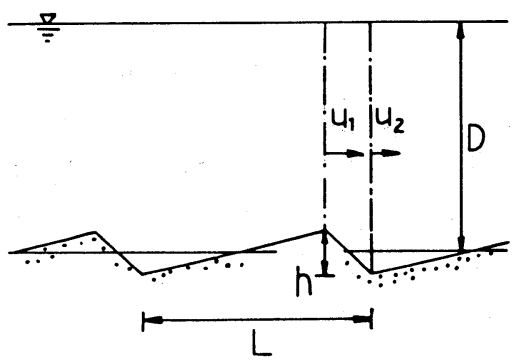

Fig.1 Notations

Fr：水流のフルード数

$r_{\mathrm{s}}$ : 砂の単位容積重量

$\varphi_{0}$ : 平坦河床での流速係数 $=7.66(\mathrm{D} / \mathrm{d})^{\frac{1}{6}}$

$r:$ 水の単位容積重量

$\tau_{*}$ : 無次元全掃流力 $=\mathrm{DS} /(\mathrm{s}-1) \mathrm{d}$

$g_{B}$ : 単位時間単位幅当 $り$ 掃流砂量

$\tau_{*}^{\prime}:$ 無次元有効掃流力

$\Phi:$ 無次元掃流砂量 $=g_{\mathrm{B}} / \sqrt{(\mathrm{s}-1) g \mathrm{~d}^{3}}$

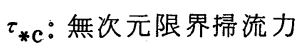

\section{3. 系の基本式}

$\tau^{\prime} ， \iota^{\prime \prime}, g_{\mathrm{B}}$, ん, Lの 5 個を未知量と考えると, これらの量からなる采を閉じるためには 5 個の式が必要 である。それらの式を以下 (a)〜 (e)飞記述する。 
（a）掃流力間の内訳式

$\tau=\tau^{\prime}+\tau^{\prime \prime}$

（b）砂堆の波長， L

前報》におらてはしして

$$
\mathrm{L} / \mathrm{d}=2 \pi(\mathrm{s}-1) \varphi_{0}{ }^{2} \tau_{*}{ }^{\prime} / 0.25
$$

を使用したが，しかし Fr=0A前後ではしは殆ど DKのみ関係し，D／d と Frkは殆ど関係しないるのとなる

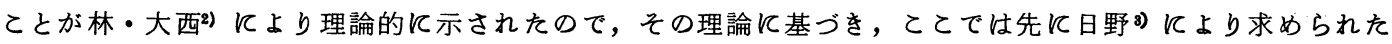
つぎの式を使用する。

$$
\mathrm{D} / \mathrm{L}=1 / 7
$$

(c) 形状抵抗" 掃流力 " $\tau^{\prime \prime}$

$\tau$ *か式としては次式を使用する。

$$
\tau * \prime \prime=\frac{h^{2}}{\mathrm{~L}^{2}} \frac{\alpha \mathrm{L}}{2(\mathrm{~s}-1) \mathrm{d}} \frac{\mathrm{U}^{2}}{g \mathrm{D}}
$$

この式は断面急拡にょる損失水頭の式

$$
h_{f}=\left(\mathrm{u}_{1}-\mathrm{u}_{2}\right)^{2} / 2 \mathrm{~g}
$$

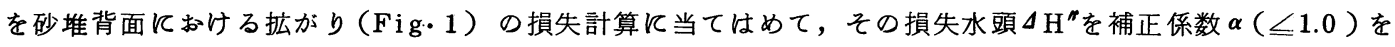
導入して,

$$
\Delta \mathrm{H}^{\prime \prime}=\alpha \frac{\left(\mathrm{u}_{1}-\mathrm{u}_{2}\right)^{2}}{2 \mathrm{~g}}
$$

とおき, これに

$$
\mathrm{u}_{1}=g /\left(\mathrm{D}-\frac{h}{2}\right), \quad \mathrm{u}_{2}=g /\left(\mathrm{D}+\frac{h}{2}\right)
$$

を代入し, さらに両辺に $(1 / \mathrm{L}) \mathrm{D} /(\mathrm{s}-1) \mathrm{d}$ をかけて無次元掃流力の次元量に書を直したるのである。

(d) 掃流砂のエネルギー方程式

Engelund・Hansen") は Bagnoldの考えを取り入れて次のような運動方程式をたてた。

掃流砂量 $g_{B}$ を波高んだけ持ち上げるのに要するエネルギーは $\left(r_{S}-r\right) g_{B}$ に等しく、同時間内に粒子に働ら く力によってなされる仕事は $\left(\tau^{\prime}-\tau_{c}\right) \mathrm{u}_{*}{ }^{\prime} \mathrm{L}$ に比例する。以上を式化すると

$$
\left(\gamma_{\mathrm{s}}-r\right) g_{\mathrm{B}} h=\alpha_{1}\left(\tau^{\prime}-\tau_{\mathrm{c}}\right) \mathrm{u}_{*}^{\prime} \mathrm{L}
$$

乙とに $\alpha_{1}$ : 比例定数

(7)式は次のように無次元化される。

$$
\begin{aligned}
g_{\mathrm{B}} h / \mathrm{L} & =\alpha_{1}\left(\tau^{\prime}-\tau_{\mathrm{c}}\right) \mathrm{u}_{*}^{\prime} \mathrm{d} /\left(\gamma_{\mathrm{s}}-\gamma\right) \mathrm{d} \\
& =\alpha_{1}\left(\tau_{*}^{\prime}-\tau_{* \mathrm{c}}\right) \sqrt{\tau_{*}^{\prime}} \sqrt{(\mathrm{s}-1) g \mathrm{~d}^{3}} \\
\Phi \frac{h}{\mathrm{~L}} & =\alpha_{1}\left(\tau_{*}^{\prime}-\tau_{* \mathrm{c}}\right) \sqrt{\tau_{*}^{\prime}}
\end{aligned}
$$

(8)式を本研究で使用する掃流砂のエネルギー方程式とする。

(e) 掃流砂量式

有効掃流力に対する掃流砂量式としてEinstein・Brown')の式

$$
\Phi=40 \tau_{*}{ }^{8}
$$

を使用する。

\section{4. 系の解}

基本式(1)，(3)（4)，(8)，(9)の 5 個の式に基づを，系の解を以下に求める。 
(a) 有効掃流力

(4)式は

$$
\begin{aligned}
\tau_{*}^{\prime \prime} & =\frac{h^{2}}{\mathrm{~L}^{2}} \frac{\alpha \mathrm{DS}^{\prime}}{2(\mathrm{~s}-1) \mathrm{d}} \frac{\mathrm{Um}^{2}}{\mathrm{gDS}} \frac{\mathrm{L}}{\mathrm{D}} \\
& =\frac{h^{2}}{\mathrm{~L}^{2}} \frac{\alpha}{2} \tau_{*}{ }^{\prime} \varphi_{\mathrm{O}}{ }^{2} \frac{\mathrm{L}}{\mathrm{D}} \\
& =\frac{h^{2}}{\mathrm{~L}^{2}} \frac{\alpha}{2} \tau_{*}{ }^{\prime}\left\{7.66\left(\frac{\mathrm{D}}{\mathrm{d}}\right)^{\frac{1}{6}}\right\}^{2} \frac{\mathrm{L}}{\mathrm{D}}
\end{aligned}
$$

と書を直される。従って

$$
\frac{h}{\mathrm{~L}}=\sqrt{\frac{2}{\alpha}} \sqrt{\frac{\mathrm{D}}{\mathrm{L}}} \frac{1}{7.66}\left(\frac{\mathrm{D}}{\mathrm{d}}\right)-\frac{1}{\sqrt{\frac{\tau_{*}^{\prime \prime}}{\tau_{*}^{\prime}}}}
$$

上式中の L / D Kは(3)式を代入し，また(4) 式の補正係数 $\alpha$ の值を

$$
\alpha \sim 0.7
$$

とすると，上式は次のように書き表わされ る。

$$
\frac{h}{\mathrm{~L}}=\sqrt{\frac{2}{4.9}} \frac{1}{7.66}\left(\frac{\mathrm{D}}{\mathrm{d}}\right)^{-\frac{1}{8}} \sqrt{\frac{\tau_{*}^{\prime \prime}}{\tau_{*}^{\prime}} \cdots(11)}
$$

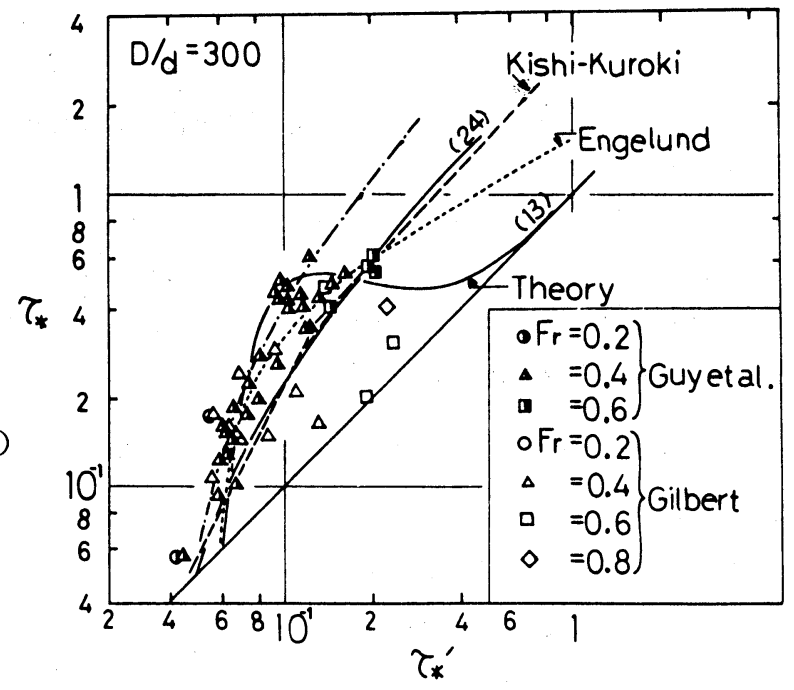

Fig. 2 Rel ation between normal ized grain-roughness shear stress and normalized total shear stress

(8)式に(1)式，(9)式，（11) 式を代入すると，

$$
40 \tau_{*}^{\prime 8} \sqrt{\frac{2}{4.9}} \frac{1}{7.66}\left(\frac{\mathrm{D}}{\mathrm{d}}\right)^{-\frac{1}{\delta}} \sqrt{\frac{\tau_{*}-\tau_{*}^{\prime}}{\tau_{*}^{\prime}}}=\alpha_{1}\left(\tau_{*}^{\prime}-\tau_{*} \mathrm{c}\right) \sqrt{\tau_{*}^{\prime}}
$$

と表わされる。上式の両辺を 2 乗してで、 ついて書を直すと全掃流力 $\tau$ と有効掃流力 でとの関係は次式で与えられる。

$$
\tau_{*}=\frac{\alpha_{1}^{2}\left(\tau_{*}^{\prime}-\tau_{*} c\right)^{2}}{1600 c_{1}^{2} \tau_{*}{ }^{\prime 4}}\left(\frac{D}{d}\right)^{\frac{1}{s}}+\tau_{*}^{\prime} \cdots \cdots
$$

ことに, $\mathrm{C}_{1}=\sqrt{2 / 4.9} / 7.66$

$\alpha_{1}=0.2$ として (13)式と Gil bert”および Guy等8)の実験值と比較したのがFig。2で ある。理論と実験との一致の度合はまだ十 分によいとはいえないが，理論は実験のあ る程度の比較曲線になりえていると思う。 図中でフルード数別にプロットしてあるが, (13)式からる分るよらに全掃流力 $\tau_{*}$ はル ード数にあまり関係しない。同図中には Engelund )

$$
\tau_{*}^{\prime}=\tau_{*} \mathrm{c}+0.4 \tau_{*}^{2}
$$

$$
\text { ただし, } \tau_{* \mathrm{c}}=0.06
$$

$$
\begin{aligned}
& \text { および, 岸・黒木11)の式 } \\
& \tau_{*}=0.21 \tau_{*}^{\frac{1}{2}} \\
& \text { (砂焳領或 I) } \\
& \tau_{*}^{\prime}=1.49(\mathrm{D} / \mathrm{d})^{-\frac{1}{4}} \tau_{*} \text { (砂堆領或I) }
\end{aligned}
$$

す併せて図示してある。これらはいずれ。

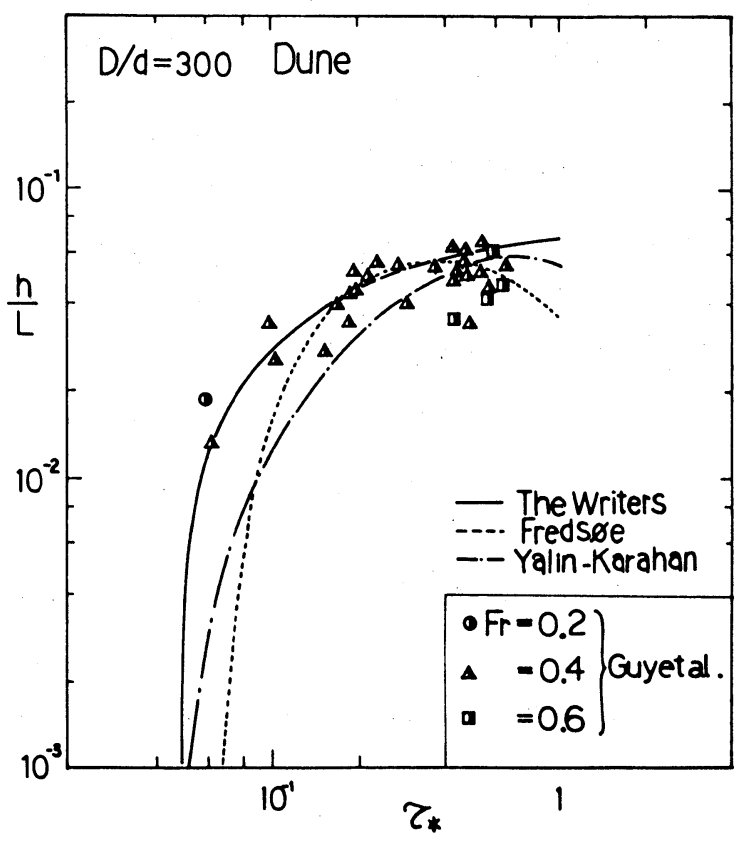

Fig.3. Comparison of predicted and observed sand wave steepnesses 
実験式であるが，限界掃流力付近の状態はこれらの式では正しく表わされない。例えばEnge lundの式 (14) では

$$
\tau_{*}^{\prime}=\tau_{*} \mathrm{c} \text { のとを } \tau_{*}=0
$$

となり理論的にはなかしいるのとなり，限界掃流力付近では同式を使用するととはでをない。ての点筆者ら の(13)式にょれば,

$$
\tau_{*}^{\prime}=\tau_{*} \text { Dとき } \tau_{*}=\tau_{*}^{\prime}
$$

となり，限界掃流力付近においても理論的な不合理は起をない。しかし，同式はでてついての 5 次式であ り，てれを解析的に解くことは極めて困難である。このため同式のでどの関係を下に示す(18)式で近似す るとととする。この関係式を図示したものがFig.2の一点鎖線の曲線である。

$$
\tau_{*}=0.90\left(\frac{D}{d}\right) \frac{1}{3}\left(\tau_{*}^{\prime}-\tau_{*} \mathrm{c}\right)+\tau_{*}{ }^{\prime}
$$

(b) 砂堆の波形勾配

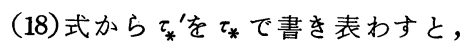

$$
\tau_{*}{ }^{\prime}=\frac{\left[\left(\tau_{*} / \tau_{*} \mathrm{c}\right)+0.90(\mathrm{D} / \mathrm{d})^{\frac{1}{3}}\right]}{1+0.90(\mathrm{D} / \mathrm{d}) \frac{1}{s}} \tau_{* \mathrm{c}}
$$

（19）式を（15）式に代入すると，砂堆の波形勾配は次式で表わされる。

$$
\frac{h}{\mathrm{~L}}=\sqrt{\frac{2}{4.9}} \frac{1}{7.66}\left(\frac{\mathrm{D}}{\mathrm{d}}\right)^{-\frac{1}{6}} \sqrt{\frac{\left(0.90(\mathrm{D} / \mathrm{d})^{\frac{1}{3}}+1\right) \tau_{*}}{\tau_{*}+0.90(\mathrm{D} / \mathrm{d})^{\frac{1}{\tau_{*}}} \tau_{*}}-1}
$$

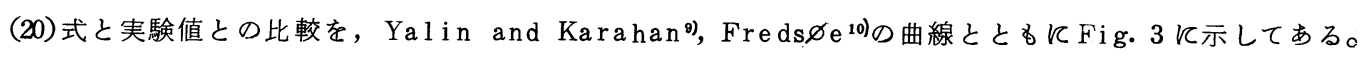

(20)式は他の 2 式と全体として似たょうな傾向を示し, 最大波形勾配は 3 式とす任㴗同じ值を見積ってい る。

(c) 掃流砂量

（19）式をEinstein・Brown の式（9）式に代入する と，全掃流力 $\tau_{*}$ 対する掃流砂量式として次の(21) 式が 与えられる。

$$
\Phi=40\left(\frac{\tau_{*}+0.9(\mathrm{D} / \mathrm{d})^{\frac{1}{\tau_{* c}}}}{0.9(\mathrm{D} / \mathrm{d})^{\frac{1}{3}+1}}\right)^{3}
$$

(21) 式と実験值との比較はFig. 4 亿点線で示すょうにな り意外なととに実験値とは全く合わない。Fig.4の実線の 上うな関係，すなわち式で表示すれば，

$$
\Phi=12\left(\frac{\left[\left(\tau_{*} / \tau_{* c}\right)+0.37(\mathrm{D} / \mathrm{d})^{\frac{1}{3}}\right] \tau_{* c}}{1+0.37(\mathrm{D} / \mathrm{d})^{\frac{1}{3}}}-\tau_{* \mathrm{c}}\right)^{\frac{3}{2} \ldots}
$$

なる関係式をうむための $\tau_{*} \sim \tau_{*}^{\prime}$ '関係式を，林・尾崎 ${ }^{14)}$ の式を簡単化した式

$$
\Phi=12\left(\tau_{*}^{\prime}-\tau_{* c}\right)^{\frac{3}{2}}
$$

を基として逆算すると，

$$
\tau_{*}=0.37\left(\frac{D}{d}\right)^{\frac{1}{z}}\left(\tau_{*}^{\prime}-\tau_{*} c\right)+\tau_{*}^{\prime}
$$

あるいは

$$
\tau_{*}{ }^{\prime}=\frac{\left[\left(\tau_{*} / \tau_{* c}\right)+0.37(\mathrm{D} / \mathrm{d})^{\frac{1}{3}}\right]}{1+0.37(\mathrm{D} / \mathrm{d})^{\frac{1}{3}}} \tau_{* \mathrm{c}}
$$

となり，Fig.2の実線のよらになるが，乙れは

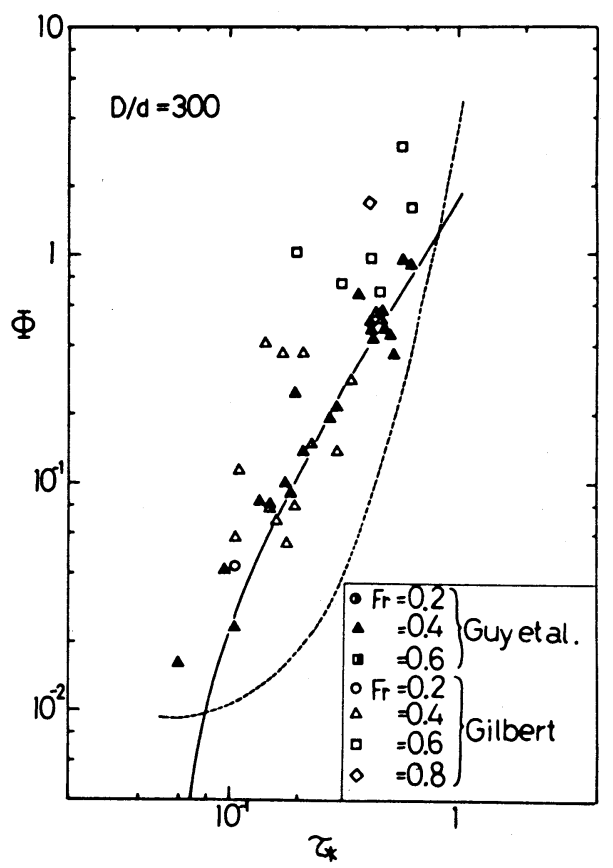

Fig. 4. Plot of normalized bed-load discharge against normalized total shear stress 
岸・黒木の式 (15)式の砂堆領域 I とII両式を曲線でつなげたようなるのとなっている。しかし同図にみられ るょうにての曲線はGilbertの実験值とはかなり合っているといえるが，Guy らの実験結果とは非常に合 わなくなっており不思議である。

\section{5. 残された問題点}

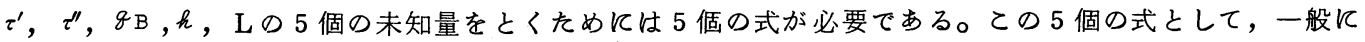
承認されていると考允られる 4 個の式(1)，(3)，(4)および(9)の他に掃流砂のエネルギー方程式(7)式を 5 番目の 式として加えて系を閉じ解を求めた。しかし，乙の掃流砂のエネルギー方程式には物理的にまだ検討の必要 が残されている上うに思われる。とてろで，固定した河床波形上の剪断力分布をプレストン管て測定するて

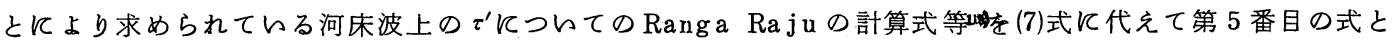
して使用するてとる考えられる。しかし，その上うな式の中には的の影響を表わす項が直接的には入って いないので，それではての采の中に８B は単にで従属変数としてのみ入っているてとになり，疑問が残る。

またでとでとの関係を図示したFig.2において, 理論式 (13)の精度についてはさらに検討が必要であ るが，改めて従来の実験值の再整理る必要なよう飞思われる。Fig. 2 と Fig.4 とを見比べるとを，Fig。 2

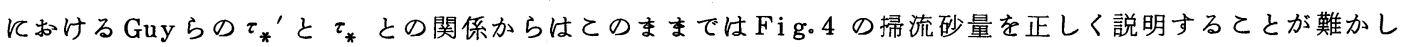
いが，その原因を検討中である。なお，掃流砂量式としては今回はEinstein・Brown 式を使ったが，より 正しくはこれを改良した林。尾崎の式 (23)式を用いて計算する方が良いと考え，ての点でる計算を改良してゅ きたい。

付記

本研究の遂行に当り, 電力中央研究所河川理境研究室尾崎幸男氏および中央大学大学院後期博士課程大西 光陽君から有益な討議を受けた。をた図面の作成にあたり同大学学部土木工学科学生井上伊佐男, 原清高, 吉田浩二の 3 君から熱心な協力をえた。記して謝意を表する。

\section{6. 引用文献}

1）林泰造・矢内栄二：河床波のSteepness K関する研究，第 34 回年次学術講演会講演集第 2 部, 1979 年 10 月, pp. $187 \sim 188$.

2）林泰造・大西光陽：小規模河床波の卓越波数につ々て，第 24 回水理講演会論文集，1980 年 2 月。

3) Hino, M. : Equilibrium - rangespectra of sand waves formed by flowing water, Jour.Fluid Mech., vol. 34, pp.565 573, 1968.

4) Engelund, Fo: Hydraulic resistance of alluvial streams, Jour. Hyd. Divo, ASCE, Vo 1.92 , No. HY2, pp. $315 \sim 326$, Mar. 1966.

5) Engelund, F. : Closure, Hydraulic resistance of alluvial streams, Jour. Hyd. Div., ASCE, Vo 1.93, No. HY4, pp.287 296, July, 1967.

6) Brown, C.B. : Engineering Hydraulics, edited by House, John Wiley \& Sons, 1950, pp.796 799 .

7) Gilbert, G.K. : Transportation of debris by runing waters, USGS professional Paper 86, 1914 .

8) Guy, H.P., Simons, D.B., and Richardson, E.V. : Summary of alluvial data from flume experiments, 1956 - 61, USGS Professional Paper 462 - 1, 1966.

9) Yalin, M.S. and Karahan, E. : Steepness of sedimentary dunes, Jour. Hyd. Div., ASCE, Vol. 105, No. HY - 4, April, 1979. 
10) Fredsøe, J. : The friction factor and height-length relations in flow over a dune - covered bed, Prog. Rep. 37, Institute of Hydrodynamics, Technical University of Denmark, Deco, 1975 .

11）岸 力・黒木幹男：移動床流れにおける河床形状と流体抵抗(I), 北大工学部研究報告, 1972 .

12) Kishi, T. : Bed forms and hydraulic relations for alluvial streams, Proc. of U.S.-Japan Binational Seminar on Erosion and Sedimentation, 1978 .

13）土木学会水理委員会移動床流れの抵抗と河床形状研究小委員会：移動床流れにおける河床形態と粗度, 土木学会論文報告集第 210 号, 1973 年。

14）林泰造・尾崎幸男: 掃流砂量に関する基礎的研究, 第 23 回水理講演会論文集, 1979 年 2 月.

15) Vittal, N., RangaRaju, K.G., and Garde, R.J.: Resistance of two dimensional triangular roughness, Jour. Hyd. Res., 15, No. 1, 1977. 